\title{
Time to Reconsider Diverse Ways of Working in Japan to Promote Social Distancing Measures against the COVID-19
}

\author{
Shuhei Nomura (D) Daisuke Yoneoka • Yuta Tanoue • \\ Takayuki Kawashima • Shoi Shi • Akifumi Eguchi • \\ Hiroaki Miyata
}

Published online: 30 June 2020

(C) The Author(s) 2020

The World Health Organization declared the outbreak of coronavirus disease 2019 (COVID-19) on March 11, 2020, highlighting the importance of preventive actions to limit the spread of infections [1]. These measures can be generally divided into those that require individuallevel efforts (e.g., handwashing, mask-wearing) and those that require social and political support (e.g. social distancing measures, including teleworking) [2,3]. On February 25, the Japanese government's basic policy for

Shuhei Nomura, Daisuke Yoneoka, Yuta Tanoue and Takayuki Kawashima shared co-first authorship

Electronic supplementary material The online version of this article (https://doi.org/10.1007/s11524-020-00464-4) contains supplementary material, which is available to authorized users.

S. Nomura $\cdot$ D. Yoneoka $\cdot$ H. Miyata $(\bowtie)$

Department of Health Policy and Management School of Medicine, Keio University, 35 Shinanomachi, Shinjuku-ku 160-8582 Tokyo, Japan

e-mail: hiroaki.miyata@gmail.com

S. Nomura

e-mail: s-nomura@keio.jp

S. Nomura · D. Yoneoka

Department of Global Health Policy, Graduate School of Medicine, The University of Tokyo, Tokyo, Japan

D. Yoneoka

Graduate School of Public Health, St. Luke's International

University, Tokyo, Japan
COVID-19 control was established; it strongly urges citizens, companies, and local communities to telework and stagger commuting hours [4].

Prime Minister Shinzo Abe declared a state of emergency in 7 of the 47 prefectures on the evening of April 7 [5] and nationwide on April 16. The declaration allows each prefectural government to request residents to refrain from going outside for non-essential reasons, but there is basically no legal means to enforce such

Y. Tanoue

Institute for Business and Finance, Waseda University, Tokyo, Japan

T. Kawashima

Department of Mathematical and Computing Science, Tokyo Institute of Technology, Tokyo, Japan

S. Shi

Department of Systems Pharmacology, Graduate School of Medicine, The University of Tokyo, Tokyo, Japan

S. Shi

Laboratory for Synthetic Biology, RIKEN Center for Biosystems Dynamics Research, Osaka, Japan

\section{A. Eguchi}

Department of Sustainable Health Science, Center for Preventive Medical Sciences, Chiba University, Chiba, Japan 


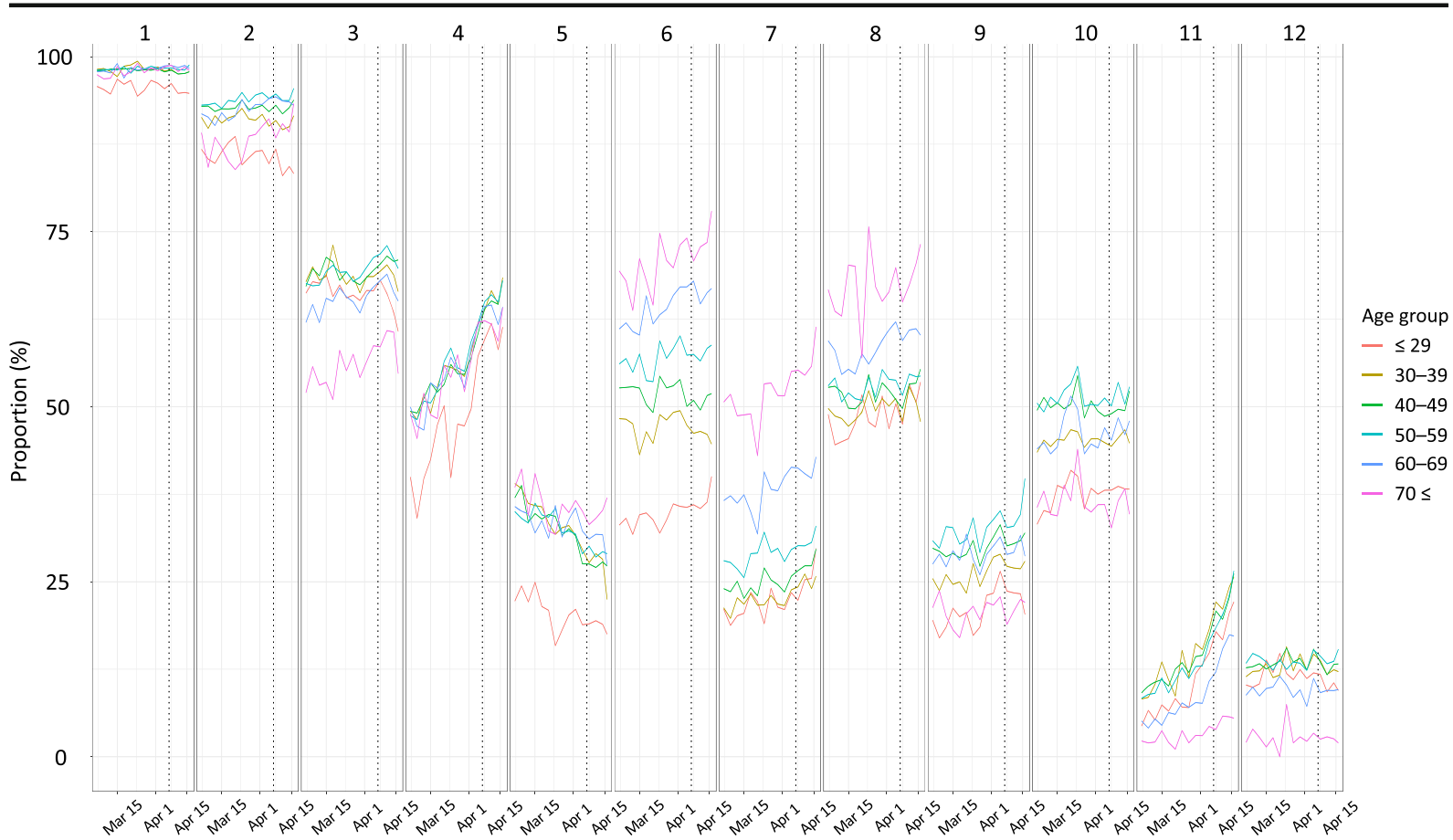

Fig. 1 Trends in the implementation rate of preventive actions. Each point is an aggregate value for every 3 days. No adjustment was implemented. 1 Hand washing and gargle; 2 cough etiquette (masks, etc.) 3 hand disinfection with alcohol; 4 regular ventilation; 5 maintaining humidity; 6 a well-balanced diet; 7 regular exercise; 8 getting plenty of rest; 9 avoidance of crowds other than staggered commuting; 10 being feasible to take time off from school or work when having symptoms of a cold, such as a fever; 11 telework; 12 staggered commuting hours. The dotted lines indicate April 7, when the state of emergency was declared $35.7^{\circ} \mathrm{N}$

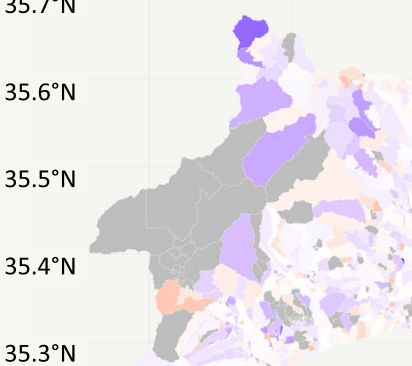

$35.6^{\circ} \mathrm{N}$

$35.5^{\circ} \mathrm{N}$

$35.3^{\circ} \mathrm{N}$

$35.2^{\circ} \mathrm{N}$
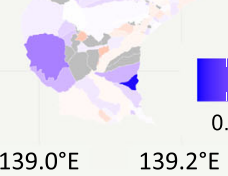

$139.0^{\circ} \mathrm{E}$

$139.2^{\circ} \mathrm{E}$

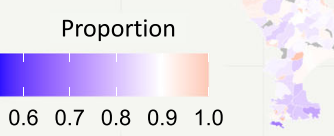

$139.4^{\circ} \mathrm{E}$

$139.6^{\circ} \mathrm{E}$

Fig. 2 Geographical distribution of the implementation rate of preventive action in the study period. Left panel: proportion of all respondents who performed both hand washing and gargle and cough etiquette (masks, etc.); right panel: proportion of telework implementation among office workers, civil servants, and part-

$35.7^{\circ} \mathrm{N}$

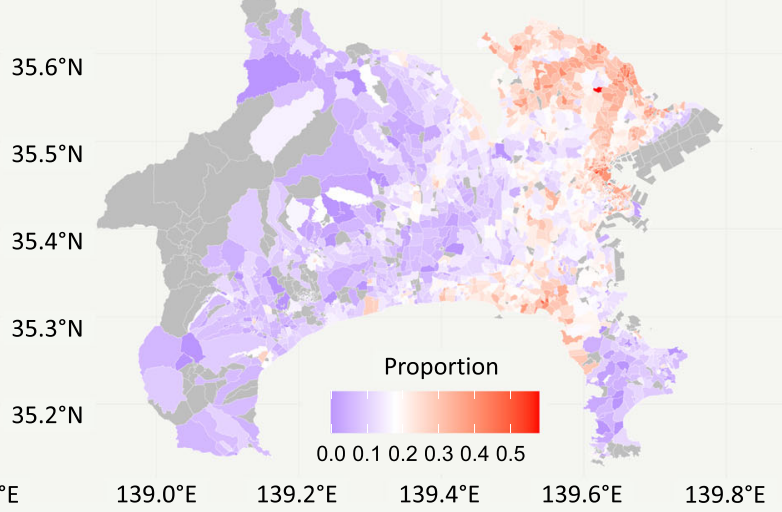

time workers. Both maps are at the post code level, with areas with fewer than 10 respondents excluded from the analysis (gray color). The range of the legends in each panel is that of the regional proportions, with the mid-point (white color) being the average 
regulations. In other words, preventive actions, including social distance measures, are largely dependent on the voluntary efforts of individuals, companies, and organizations.

\section{Methods}

On March 5, 2020, in response to the spread of COVID19, Kanagawa Prefecture (the second most populous prefecture in Japan after Tokyo, with approximately 9 million people, and one of the prefectures subject to the early declaration of a state of emergency) launched a personalized support program through LINE's chatbot (Japan's largest social communication application with 83 million active users, accounting for $65 \%$ of the Japanese population) [6]. Geographical scope of the location of Kanagawa Prefecture is presented in Fig. $\mathrm{S} 1$. A questionnaire is provided through the application inquiring about the user's physical condition, and what actions they are currently taking to prevent infections. Based on the content of the initial responses, each user will receive a follow-up questionnaire or be directed to a consultation desk and provided with personalized information on how to prevent the infection. More details of this LINE service can be found elsewhere [7].

We received data from Kanagawa and analyzed the initial response data of 431,106 individuals aged over 15 years until April 16, 2020 to assess the extent to which preventive actions are being taken and how they have changed over a month, including the date of the declaration of a state of emergency in Kanagawa (April 7). Figure S2 shows the cumulative number of respondents by day in the study period.

\section{Results}

The results show that handwashing and cough etiquette are quite widespread preventive actions, as about $90 \%$ of all age groups were practicing them (Fig. 1). On the other hand, only about half of the respondents reported that it was not feasible to take leave in case of cold symptoms, and only about less than $20 \%$ of the respondents answered that telework and staggering commuting hours was feasible for them, although a slight improvement was observed during the study period. The declaration of the state of emergency did not have a clear influence on this trend, and excluding those who do not work did not change our conclusions.

Figure 2 shows the geographical distribution of the implementation rate of preventive actions. While there was relatively little geographical variation in the implementation of handwashing and cough etiquette, there was a remarkable difference in the implementation of telework between eastern area around the prefectural capital and other areas.

\section{Discussion}

It should be noted that this data was collected from LINE users in Kanagawa who voluntarily responded in the early stages of the program and may not be representative of the population of Japan as a whole, or of Kanagawa Prefecture. It is also necessary to note that this analysis did adjust for confunding variables that may change over time or geographically (e.g., changes in temperature; during the study period, it was spring in Japan and the temperature was on an upward trend). These findings might indicate that for preventive actions that can be implemented with individual efforts, many of them have already been successfully implemented. However, preventive actions such as teleworking that require more social and political efforts are much more difficult to implement on an individual basis. Therefore, social and political support to promote flexible working practices is an urgent issue that is expected to play a crucial role in curbing the spread of COVID-19 in Japan.

Acknowledgments We would like to thank Kanagawa Prefecture for providing us with data. This study was funded by the Ministry of Health, Labour and Welfare of Japan (H29Gantaisaku-ippan-009).

Author Contributions All authors had full access to all of the data in the study and take responsibility for the integrity of the data and the accuracy of the data analysis.

Concept and design: Dr. Nomura, Dr. Yoneoka, Dr. Tanoue, Dr. Kawashima, Dr. Eguchi, Dr. Shi.

Acquisition, analysis, or interpretation of data: All authors.

Drafting of the manuscript: Dr. Nomura, Dr. Yoneoka, Dr. Eguchi.

Critical revision of the manuscript for important intellectual content: All authors.

Statistical analysis: Dr. Nomura, Dr. Yoneoka.

Administrative, technical, or material support: Dr. Nomura, Dr. Miyata.

Supervision: Dr. Miyata. 


\section{Compliance with Ethical Standards}

Disclaimer The funding organization had no role in the design and conduct of the study; collection, management, analysis, and interpretation of the data; preparation, review, or approval of the manuscript; or decision to submit the manuscript for publication.

Ethics Statement Ethical approval was granted by the ethics committee of Keio University School of Medicine, under authorization number 20190338. We only obtained data from those who have given consent for the prefecture that administers the questionnaire to provide their response data to a third party for research use. Respondents must give their consent on the LINE chatbot before they proceed to the questionnaire response page.

Open Access This article is licensed under a Creative Commons Attribution 4.0 International License, which permits use, sharing, adaptation, distribution and reproduction in any medium or format, as long as you give appropriate credit to the original author(s) and the source, provide a link to the Creative Commons licence, and indicate if changes were made. The images or other third party material in this article are included in the article's Creative Commons licence, unless indicated otherwise in a credit line to the material. If material is not included in the article's Creative Commons licence and your intended use is not permitted by statutory regulation or exceeds the permitted use, you will need to obtain permission directly from the copyright holder. To view a copy of this licence, visit http://creativecommons.org/licenses/by/4.0/.

\section{References}

1. World Health Organization. WHO Director-General's opening remarks at the media briefing on COVID-19 - 11 March 2020. World Health Organization. https://www.who. $\mathrm{int} / \mathrm{dg} /$ speeches/detail/who-director-general-s-opening-
remarks-at-the-media-briefing-on-covid-19\%2D\%2D-11march-2020. Published 2020. Accessed May 25, 2020.

2. World Health Organization. Coronavirus disease (COVID19) advice for the public. World Health Organization. https://www.who.int/emergencies/diseases/novelcoronavirus-2019/advice-for-public. Published 2020. Accessed May 25, 2020.

3. World Health Organization. Getting your workplace ready for COVID-19: how COVID-19 spreads, 19 March 2020. Geneve, Switzerland: World Health Organization; 2020-0319; 2020.

4. Office for Pandemic Influenza and New Infection Diseases Preparedness and Response, Cabitnet Secretariat. Basic Policies for Novel Coronavirus Disease Control. Cabinet Secretariat. https://www.mhlw.go.jp/content/10200000 /000603610.pdf. Published 2020. Accessed May 25, 2020.

5. Cabinet Secretariat. Press Conference by the Prime Minister Regarding the Declaration of a State of Emergency. Cabinet Secretariat. https://japan.kantei.go.jp/98 abe/statement/202004/_00001.html. Published 2020. Accessed May 25, 2020.

6. Kanagawa Prefecture. LINE support for individualized countermeasures against the new corona [Japanese]. Kanagawa Prefecture. https://www.pref.kanagawa.jp/docs/ga4 /bukanshi/line/index.html. Published 2020. Accessed May 25, 2020.

7. Yoneoka D, Kawashima T, Tanoue Y, Nomura S, Ejima K, Shi S, et al. Early SNS-based monitoring system for the COVID-19 outbreak in Japan: a population-level observational study. J Epidemiol. 2020. https://doi.org/10.2188/jea. JE20200150. Online ahead of print.

8. Ministry of Health, Labour and Welfare. Result of the 1st -4 th national surveys for COVID-19. https://www.mhlw.go. jp/stf/newpage_11244.html. Published 2020. Accessed May 25, 2020.

Publisher's Note Springer Nature remains neutral with regard to jurisdictional claims in published maps and institutional affiliations. 